\title{
The Use of Museum Specimens for Marine Education
}

\author{
Ayano Omura 1* \\ ${ }^{1}$ Department of Design, Nihon University College of Art, Tokyo, JAPAN
}

*Corresponding Author: cuttlefish.ayano.o@gmail.com

Citation: Omura, A. (2019). The Use of Museum Specimens for Marine Education. Pedagogical Research, 4(3), em0035. https://doi.org/10.29333/pr/5836

Published: June 29, 2019

\begin{abstract}
Today, the necessity of marine education is being stated. Especially raising awareness about biodiversity is important in marine education. Museums not only house exhibits but also have the function of storing specimens. They hold specimens not available to the public daily that can be used for educational and research purposes. Samples of creatures that are difficult to keep and of unusual organisms are often stored in museums. Also, since immersion specimens do not move, they are suitable for observation. The forms of fish are especially diverse. Observations of fish of various forms facilitate the understanding of fish morphology and awareness of biodiversity. Therefore, we conducted a marine biology course using museum fish specimens. In that course, in order to encourage learners' activeness, we implemented quizzes and organized sessions with story nature. Before the lecture, the awareness of the morphology of the fish was low. The lecture was able to make the diversity of fish form understanding. Learners actively attended, observed and deepened their understanding. Also, we were able to tell learners about the function of the museum. It was found that the use of museum specimens is beneficial for observing precious biological specimens.
\end{abstract}

Keywords: marine education, museum specimens, morphology, biodiversity, fish

\section{INTRODUCTION}

Japan is an ocean country, and the necessity for marine education is currently increasing (Kohno et al., 2016). In order to raise awareness of the need for conservation of the marine environment, it is also necessary to raise awareness of marine life and biodiversity (Kohno et al., 2016; Lück, 2015; Murray et al., 1999; Shimada, 2009). There is a wide variety of sea creatures. Among them, fish are regarded as representative of marine life, and they are familiar through fishing and other common Japanese activities. In addition, the number of fish species is overwhelming among vertebrates, and their shapes show great diversity (Magurran, 2004; Matsuura, 2005; Sfakiotakis et al., 1999). Indeed, both the sizes and the forms of fish are very diverse; the smallest fish is about 8 $\mathrm{mm}$ long (Paedocypris progenetica), and the largest fish is a whale shark (Rbincodon typus), reaching over $13 \mathrm{~m}$ in length (Matsuura, 2005). Therefore, it is useful to explain fish as an introduction to the diversity of the shapes of marine life.

An aquarium is an important facility to observe marine life. One of the role of the aquarium is education (Rahm and Ash, 2008; Dohn, 2011; Karydis, 2011). Many kinds of marine life are raised in aquariums, and thus they are very well suited for people to see their living appearance (Adelman, Falk, and Sylvia, 2000; Falk and Adelman, 2003; Suzuki and Nishi, 2010). However, it is difficult for aquariums to display species that are difficult to keep (Uchida and Arai, 2014). Also, since sea life in an aquarium is alive, it is difficult for children to observe all the detail intended. 


\section{Which is fish?}

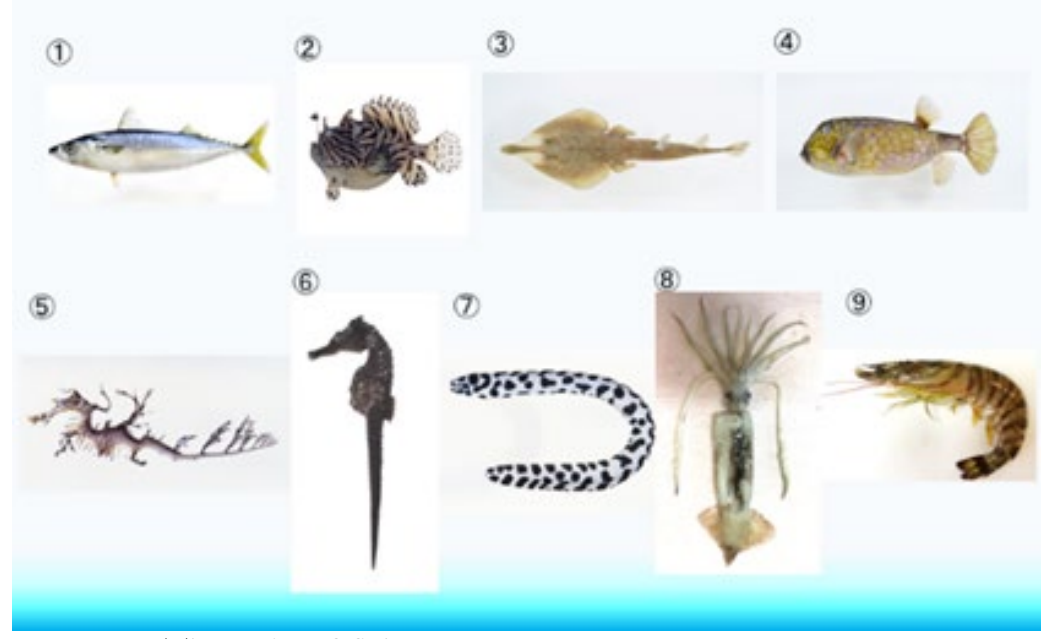

Figure 1. The quiz of fish

Therefore, from the perspective of using specimens for education, museums can be important. The advantage of museum specimens is that there are so many kinds of specimens available that educators can choose specimens that are suitable for their educational purpose. The museum has the role of collecting, storing, exhibiting, researching, and conducting education on their specimens (Chattejee, 2010; Ohori and Mizushima, 2014; Suarez and Tsutsui, 2004). Museums thus provide many opportunities for visitors to see those specimens that are on regular display (Alcaraz, Hume, and Mort, 2009). Many specimens specific to the museum are stored in the museum, but visitors are less likely to see them.It is not widely known that there are many specimens besides exhibition places. Therefore, it is considered very useful to use immersion specimens stored in the museum for education on marine life. Setting up the opportunity to "observe a museum specimen" will also help children learn about the role of the museum, as well as boost motivation to participate in research.

In order to learn about nature, it is important to actually observe the real thing (Furihata, Miyano, et al., 2009). Observation can enhance comprehension (Ogawa, 2009). Although it is most desirable to actually see nature in real life, a lecture is also useful for observing rare specimens well. Therefore, movable and long-storable museum specimens are very useful for education.

Also, to raise learners' willingness to learn, it is important not only to describe educators unilaterally but also interactive communication and learners themselves to move thinking (Sunaga, 2010). To raise learners' motivation, it is reported that it is useful to extract interests by taking games and quizzes (Boctoar, 2013; Furihata, 2009b). Therefore, incorporating quizzes in courses is considered to be helpful in eliciting learner motivation. Also, the story of the lecture is vital for learning (Negete and Lartigue, 2004; Susono, Simoura, et al., 2006). Thus, a learning story that introduces a quiz and observes a real museum sample after giving the impression that various fish are present seems to have a very high learning effect.

Therefore, in this paper, we report on a marine education course conducted using museum specimens at a lifetime learning institution during the summer of 2018.

\section{MATERIALS AND METHODS}

The lecture was held in the summer lecture on marine life of a lifetime learning institution, the Gakushuin Sakura Academy in 2018. First, we gave a quiz on the "Morphological recognition of fish" to convey that there are various forms of fish. The quiz covers fish with a variety of common shapes (Figure 1): (1) Chub mackerel (Scomber japonicus) (KPM-NR 108549): a typical streamlined fish; (2) Frogfish (Antennarius hispidus) (KPM-NR 53467A): a fish shaped like a rugged rock; (3) Brown guitarfish (Rhinobatos schlegelii) (KPM-NR 108564A): a flat fish (ray); (4) Boxfish (Ostraciidae Rafinesque) (KPM-NR 108824A): a square fish like a box; (5) Leafy sea dragon (Phycodurus eques) (kPM-NR 57904A): a seaweed-like fish; (6) Seahorse (Hippocampus. kuda) (KPM-NR 45458A): a dragon-like fish: (7) Spotted moray (Gymnothorax isingteena) (KPM-NR 50146B): a slender fish with small black dots; (8) Japanese common squid (Todarodes pacificus): a slender cephalopod, not a fish; and (9) Kuruma prawn (Marsupenaeus japonicus): a slender swimming crustacean, not a fish. The images of Frogfish, Brown guitarfish, Boxfish, Leafy sea dragon, Seahorse and Spotted moray belong to Kanagawa Prefectural Museum of natural History. 


\section{Museum Specimen}

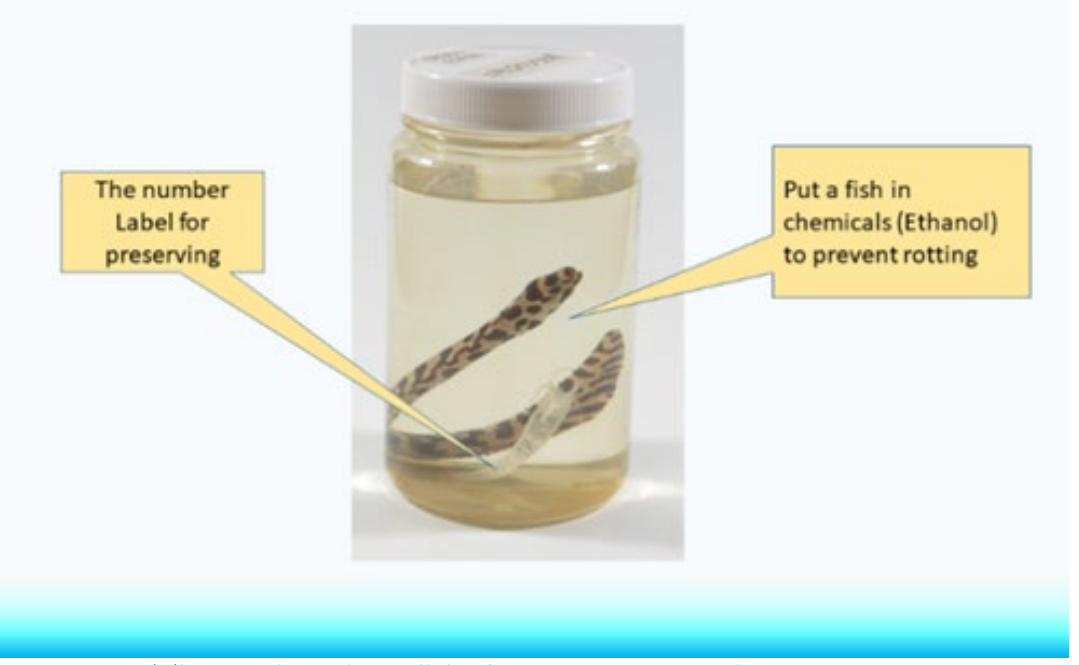

Figure 2. The explanation slide for museum specimens

After giving the correct answers, time was taken to observe specimens of the rare fish on the quiz, with explanations of the diverse morphology and ecology of fish. We distributed magnifying glasses for observation. The specimens used for observation were museum specimens. The specimens were borrowed (Frogfish: KPM-NI 7763, Brown guitarfish: KPM-NI 10029, Boxfish: KPM-NI 43753, Leafy sea dragon: KPM-NI 17310, Seahorse: KPM-NI 29444 and Spotted moray: KPM-NI 2028) species name, number) from the Kanagawa Prefectural Museum of Natural History in July. Specimens were fixed in 10\% formalin and stored in $70 \%$ ethanol. In order to facilitate observation in the course, aging yellowed ethanol was replaced with new colorless and transparent $70 \%$ ethanol.

After the course, we gave a 5-point scale (excellent, good, average, below average, poor) questionnaire on the participants' degree of impression, comprehension, and free description of opinions.

\section{Observation Points and Explanations}

Museum Specimens: The museum specimens were preserved according to the policies and objectives of the museum. In the case of fish, they are preserved mainly as immersion specimens, but other skeletal specimens and shells from scallop and other shellfish are also preserved as specimens. In the case of immersion specimens, they are prepared for preservation, mainly in ethanol alcohol, for long-term storage. Specimens are assigned registration numbers for control purposes (Figure 2).

Observation the specimens: The morphology of a lifeform often reflects the functions it needs for survival. This theory has been observed to hold many times in aquatic and marine life (Omura, Anzai, and Endo, 2014; Omura, Anzai, Koyabu, and Endo, 2015a,b; Omura, Ejima, et al., 2015; Omura and Endo 2016). Therefore, we showed various shapes and explained the convenience of each shape. The explanations were from Helfman, Collette, et al. (2009).

Frogfish (Antennarius hispidus) (KPM-NI 7763) (Figure 3A): The first dorsal fin has changed to a fishing lure called an esca (Figure 3B). Frogfish resemble rocks, and this camouflage can protect them from predators and help lure prey. They also have a thick pectoral fin and walk on the ocean floor. We made children focus on the overall shape and the pectoral fin.

Brown guitarfish (Rhinobatos schlegelii) (KMP-NI 10029) (Figure 3C): These are from a family of rays: cartilaginous fish. They have an elongated body, flattened head, and ray-like wings.

Boxfish (Ostraciidae Rafinesque) (KPM-NI 43753) (Figure 3D): They look like a square box. Their swimming ability is poor, but their body surface is hard, helping protect them from predators.

Leafy sea dragon (Phycodurus eques) (KPM-NI 17310) (Figure 3E): They mimic seaweed. Their shape as they drift in the sea is like seaweed. They swim slowly, and their appearance is that of floating algae to deceive the eyes of predators. They swim with their fins.

Seahorse (Hippocampus. kuda) (KPM-NI 29444) (Figure 3F): This is a member of the seahorse family. Seahorses are widely recognized sea organisms, but it is not commonly known that they are fish. The surface of their body is hard and uneven. A tubular snout protrudes forward, and their mouth is at the end of the snout. They have no caudal fin, but they do have a small dorsal fin on the dorsal side and pectoral fins around the neck. 
A

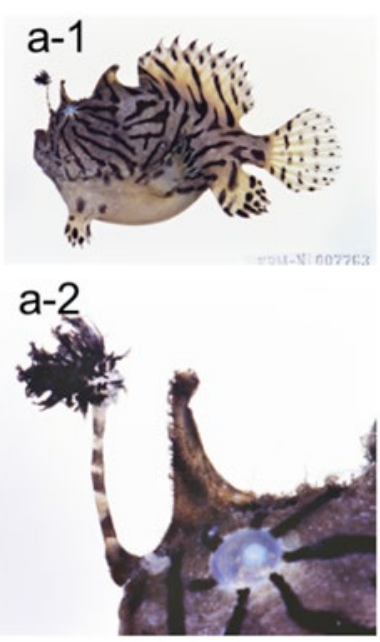

B

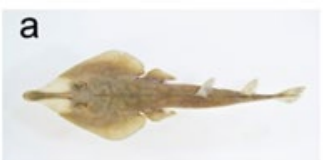

b

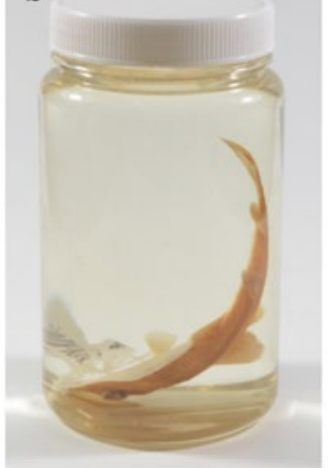

C

a

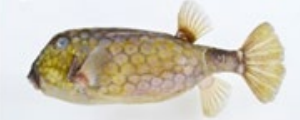

b

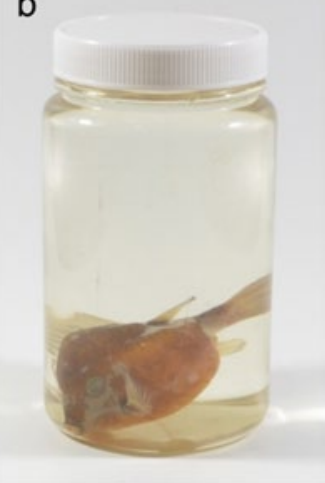

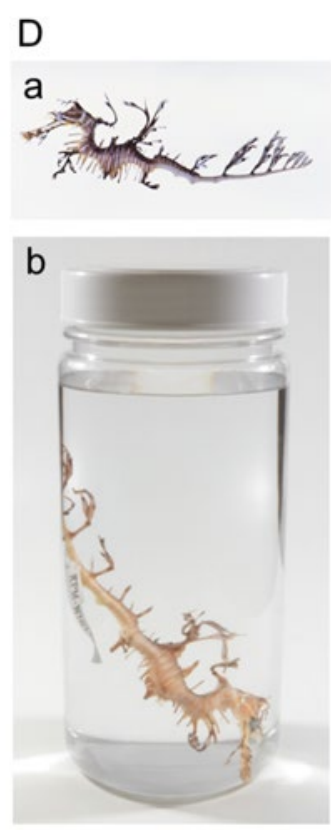

E

a

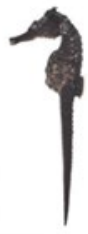

b

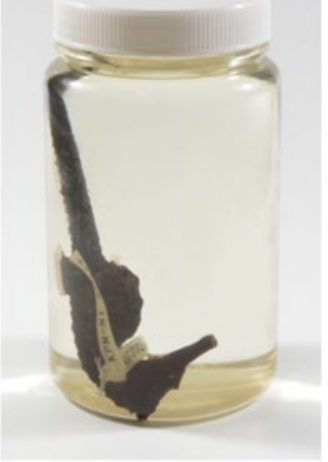

F

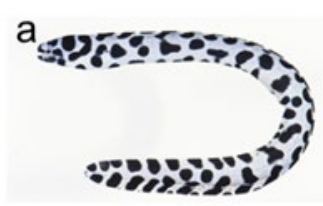

b

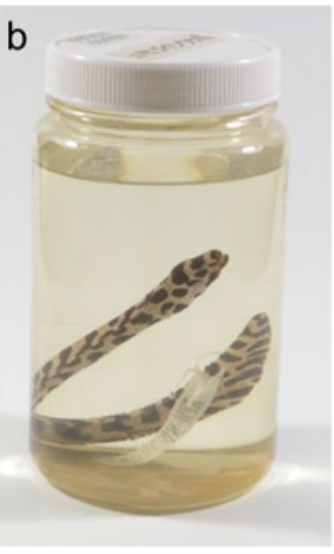

Figure 3. Museum specimens observed. A: Frogfish (Antennarius hispidus) (KPM-NR 53467A,B = KPM-NI 7763) B: Brown guitarfish (Rhinobatos schlegelii) (KPM-NR 108564A = KPM-NI 38497), C: Boxfish (Ostraciidae Rafinesque) (KPM-NR 108824A, KPM-NI 43753), D: Leafy sea dragon (Phycodurus eques) (KPM-NR 57904A = KPM-NI 17310), E: Seahorse (Hippocampus kuda) (KPM-NR 45458A = KPM-NI 29444) F: Spotted moray (Gymnothorax isingteena) $($ KPM-NR $50146=$ KPM-NI 2028), a: a picture of specimens, b: museum specimens observed by learners

Spotted moray (Gymnothorax isingteena) (KPM-NI 2082) (Figure 3G): This is an elongated fish. Fish with an elongated shape are well-suited to entering narrow places and burrowing into the sand. They have sharp teeth and a big mouth.

\section{RESULTS}

Figure 4 shows the correct answer rate of the quiz. The numbers of people who answered each fish correctly out of 16 participants are: (1) Chub mackerel (Scomber japonicus): 100\% (16 of the 16 people), (2) Frogfish (Antennarius hispidus): $18.8 \%$ (3 of the 16 people), (3) Brown guitarfish (Rbinobatos schlegelii): $50.0 \%$ (8 of the 16 people), (4) Boxfish (Ostraciidae Rafinesque): $62.5 \%$ (10 of the 16 people), (5) Leafy sea dragon (Phycodurus eques):6.25 $\%$ (1 of the 16 people), (6) Seahorse (Hippocampus. kuda):12.5\% (2 of the 16 people), (7) Spotted moray (Gymnothorax isingteena): $68.8 \%$ (11 of the 16 people), (8) Japanese Common Squid (Todarodes pacificus): $100 \%$ (16 of the 16 


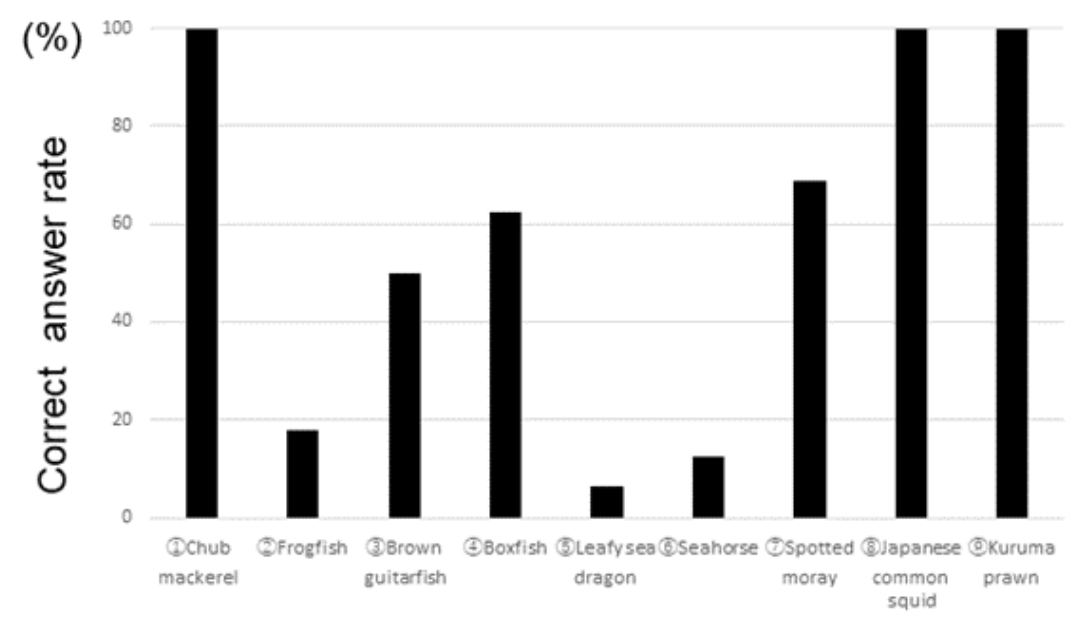

Figure 4. The correct answer rate of the quiz

$(\%)$

100

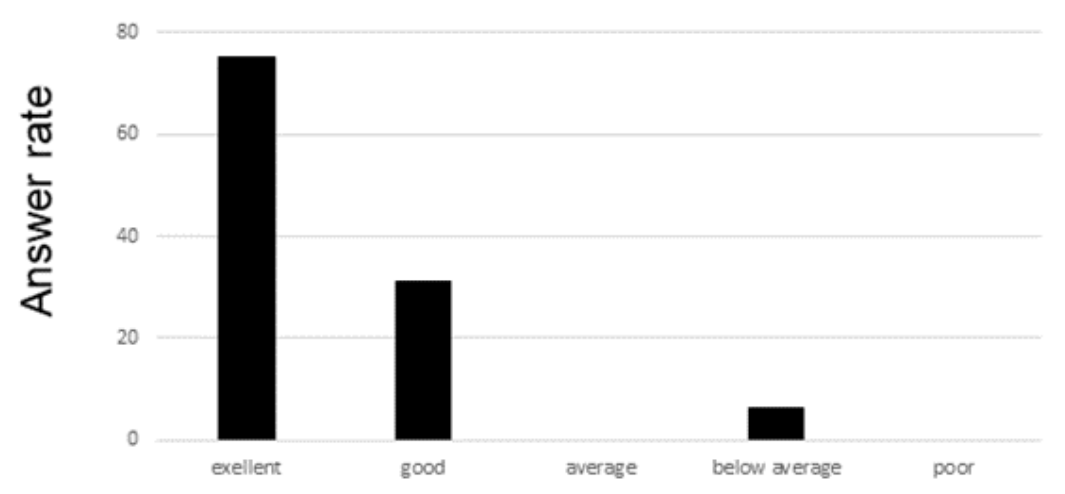

Figure 5. The answer rate of the questionnaire survey of the impression

people), (9) Kuruma prawn (Marsupenaeus japonicus): 100\% (16 of the 16 people). After conducting the observation and explanations, we gave the same quiz again, and everyone answered all questions correctly. Children were surprised to learn that (1) to (7) were all "fish."

When we showed them the specimens, a voice said "It is a dead body." To have a better view of the specimens, students observed them keenly with a magnifying glass. In particular, there were many children who looked at the Leafy sea dragon for a long time.

\section{Questionnaire Survey}

Figure 5 shows the answer rate of the questionnaire survey of the impression. According to the answers on the survey of the impression of the course, $75 \%$ (12 of 16 people) answered it was excellent, $18.8 \%$ ( 3 people) answered it was good, and $6.3 \%$ (1 1 f 16 people) said that it was poor. Figure 6 shows the answer rate of the questionnaire survey of the comprehension. Comprehension about the various forms of fish, $87.5 \%$ (14 of 16 people) answered that it was excellent and $12.5 \%$ ( 2 to 16 people) said it was good. In the free description, representative answers include, "I saw the specimens of the museum for the first time," "I learned that there was not only the exhibition space but also space in the back of the museum," and "It was very good that I could see many rare fish specimens." Among the opinions, one student wrote, "I wanted to see an animation of the fish when swimming." 


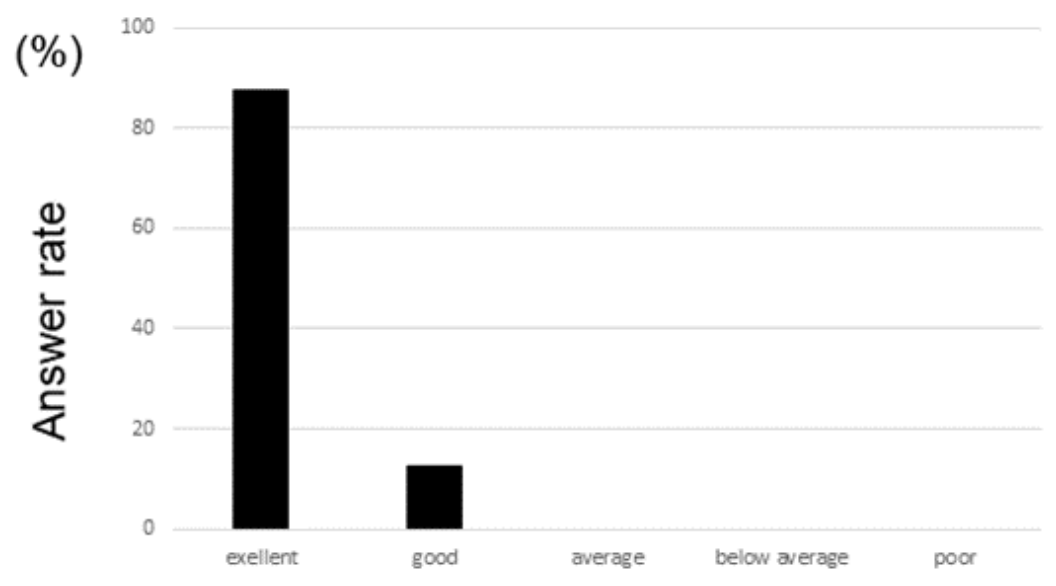

Figure 6. The answer rate of the questionnaire survey of the comprehension

\section{DISCUSSION}

In the quiz we gave the students on fish, they recognized typical streamlined fish as fish, but before our explanations other forms of fish were not so recognized (Figure 4). With this course, we were able to make students understand that fish have a variety of forms. The recognition that there are various kinds of marine life is the basis of understanding biodiversity at first (Gayfold, 2010; Iwama, 2008). Therefore, we consider that showing various forms of fish, as in this course, not only teaches fish biology but also leads to a future understanding of biodiversity.

To recognize nature, learners start with observation (Omura, 2016). It is considered very important that learning involve hands-on experiences such as observation and experimentation (Seonar and Muto, 1998). Thus, providing an opportunity to actually observe specimens as in this course is useful for learning (Furihata, 2003). However, it is difficult to obtain specimens to observe rare fish carefully as in this course. Although usefulness as an educational material such as small dried sardines "dissection and "Chirimen monster" of dried young sardines has been reported, there are problems that it is difficult to qualify because the target organism is small (Saeki, Imamura, 2013; Saeki, 2017). Also, the available fish species are limited. It seems that the use of the museum specimen was beneficial to make it easy to observe with the naked eye or the magnifying glass and to use the specimen meeting the story intended by the educator as teaching material.

When we showed the specimen at the beginning, there was a voice from one student, "It is a dead body." The fish that children usually see are in fish markets, aquariums (Kamezaki \& Nakamura, 2017), pet shops, etc. Therefore, it appears that the opportunity to see scientifically preserved immersion specimens was very valuable. In particular, it seemed to interest the students when it was explained that chemicals were used to prevent the specimens from decaying, and it was possible to tell them how to preserve specimens so as to study living organisms for scientific research. In addition, it seems that the children became interested in the role of the museum.

Seas and aquariums are famous as a place of marine education (Uchida, Arai, et al., 2014), but a variety of fish specimens are stored in a museum like Kanagawa Prefectural Museum of Natural History, which is focusing on fish collections. As one of the usages of the museum, what we could introduce to the students seems to have been helpful for the participants to increase learning opportunities in the future.

Also, according to the questionnaire results, there were many answers that the impression and comprehension of the course was excellent or good. The necessity for active learning is required in recent years (Koyama and Mizokami 2017). It is thought that learning by themselves and real experience is useful for learning rather than a one-way explanation of educators (Koyama and Mizokami 2017). Therefore, it seems that using quizzes to convey the impression that there are various forms of fish was useful in drawing interest. There are many reports on the usefulness of quizs for learning (Papastergiou, 2009; Okazaki, 2017), and learning can be enjoyed fun if there is the game character and story nature (Negete and Lartigue 2004; Susono et al., 2006). In this course, we introduced a quiz and set up a learning story of impressing the diversity of fish and observing the real thing. This story making and exam and specimen observation seem to be useful for learning.

Today, the need for marine education for young people who will be responsible for the next generation is stated for sustainable fisheries resources and environmental conservation (Kohno et al., 2016). In order to preserve the marine environment, knowledge and understanding of biodiversity are indispensable (Iwama et al., 2008), so it is important to take the content of biodiversity as part of marine education. Showing the existence of various forms 
of fish, telling the functional morphological adaptations of fish shape, and giving the opportunity of actually observing were useful as marine education for the first scholars.

We conducted a lecture on marine life and examined the utility of museum specimens for marine education in this study. Many specimens that are valuable and useful for education are collected in museums (Alcaraz, Hume, and Mort, 2009), but it is difficult to obtain access to them normally. Therefore, it appeared that it would be extremely useful for educators to use museum specimens to show learners specimens suitable for their teaching purposes. In the future, we would like to collaborate with other educational institutions such as aquariums and conduct further developed lectures.

\section{ACKNOWLEDGEMENTS}

We thank Dr. Hirosi Senou of Kanagawa Prefectural Museum of Natural History for giving useful advice and lending specimens for the lecture. We also thank Dr. Kazushi Shibagaki of the Sakura Academy of the Gakushuin University for providing the opportunity of the lecture. We also thank Dr. Takanori Maehara for giving us the useful advice of the statistical test. The author would like to thank EDITAGE for the English language review. The study was conducted by the Sasakawa Scientific Research Grant, THE JAPAN SCIENCE SOCIETY $<$ number 2018-8027>.

\section{REFERENCES}

Adelman, L. M., Falk, J. H. and Sylvia, J. (2000) Impact of National Aquarium in Baltimore on Visitor's Conservation Attitudes, Bahavior, and Knowledge. The Museum Journal, 43(1), 33-61. https://doi.org/10.1111/j.2151-6952.2000.tb01158.x

Alcaraz C., Hume M. and Mort G. S. (2009) Creating Sustainable Practice in a Museum Context: Adopting Servicecentricity in Non-profit Museums. Australian Marketing Journal, 17, 219-225. https:// doi.org/10.1016/j.ausmj.2009.06.003

Chattejee, H. J. (2010) Object-based learning in higher education: The pedagogical power of museums. University Museums and Collections Journal, 3, 179-181.

Dohn, N. (2011) Situational Interest of High School Students Who Visit an Aquarium. Science Educatoin, 95(2), 337-357. https://doi.org/10.1002/sce.20425

Endo H., Omura A., Sakai T., Itou T., Koie H., Iwata H. and Abe Y. (2012) The Differences of the Functionalmorphological Strategy between the First and Second Dorsal Fins of the Living Coelacanth (Latimeria chalumnae). Japanese Journal of Zoo and Wild Medicine, 17(2), 79-86. https://doi.org/10.5686/jjzwm.17.79

Falk, J. H. and Adelman, L. M. (2003). Investigating the Impact of Prior Knowledge and Interest on Aquarium Visitor Learning. Journal of Research in Science Teaching, 40(2), 163-176. https:/ / doi.org/10.1002/tea.10070

Furihata, S, Miyano, J, Nojo, A. and Fujii, H. (2009). Learning Through Experiencing Nature from the Standpoint of Environmental Education: Task and Forecast. Japanese journal of Environmental Education, 19(1), 3-15. https://doi.org/10.5647/jsoee.19.1_3

Furihata, S. (2003) An Introduction of the History of Nature Game's Progress as an Environmental Education Program in Japan. Japanese journal of Environmental Education 12(2), 3-14.

Gayford, C. (2010) Biodiversity Educatoin: A teacher's perspective. Environmental Educational Research 6(4), 347-361. https://doi.org/10.1080/713664696

Helfman, G., Collette, B. B., Facey, D. E. and Bowen, B. W. (2009) The Diversity of Fishes: biology, evolution, and ecolog, The United States: John Wiley \& Sons press.

Iwama, J., Matsubara, S. and Shimojo, T. (2008). State of Teaching Materials on Animals to Elementary School Science Textbooks Viewed from a Notion of Biodiversity: Aiming at Development of Science Textbooks Enhancing Children's Interest" Science Education, 32(1), 27-38. https:// doi.org/10.14935/jssej.32.27

Jiménez-Aleixandre, M. P. and Crujeiras, B. (2017). Epistemic practices and scientific practices in science education. Science Education, 69-80. https://doi.org/10.1007/978-94-6300-749-8_5

Kamezaki, N. and Nakamura, K. (2017). Educational program of animal phylogenetic taxonomy in the aquarium. Learning the evolution of animals while observing the living specimens. Bulletin of Okayama University of Science 1,11-18.

Karydis, M. (2011). Organizing a public aquarium: Objectives, design, operation and missions. A review design, operation and missions. A review. Global NEST Joumal, 13(4), 369-384. https://doi.org/10.30955/gnj.000702

Kohno, H., Yatabe, A., Kase, Y. and Saito, Y. (2016). Fish Transparent Specimens Are Effective in Marine Environmental Education: Obluteserving Prey-predator Relationships in Coastal Waters. Journal of the Tokyo University Marine Science and Technology, 12, 4-11. 
Koyama, A. and Mizokami, S. (2017). Effects of Students' Attitudes in "Lecture" and "Active Learning" on Learning Outcomes: Results of the Questionnaire Surveys at a Junior College. Bulletin of Nagoya Eduucation, 17, 101-121. https://doi/10.18999/njhe.17.101

Lück, M. (2015). Ocean \& Coastal Management Education on marine mammal tours; But what do tourists want to. Ocean and Coastal Management, 103, 25-33. https://doi.org/10.1016/j.ocecoaman.2014.11.002

Magurran, A. E. (2004). Measuring Biological Diversity. Oxford: Blackwell Publishing.

Matsuura, K. (2005). Morphological diversity of fishes, Japan: Tokai University Press.

Murray, B. S. N., Ambrose, R. E., Bohnsack, J. A., Botsford, L. W., Carr, H., Davis, G. E. and Yoklavich, M. M. (1999). No-take Reserve Networks: Sustaining Fishery Populations and Marine Ecosystems. Fisheries Management, 24(11), 11-25. https:// doi.org/10.1577/1548-8446(1999)024<0011:NRN>2.0.CO;2

Negrete, A. and Lartigue, C. (2004) Learning from education to communicate science as a good story. Endevoer 28 , 3, 120-124. Ogawa, K. (2009) Some Viewpoint of Environmental Education Considered from Development of Nature Conservation Education in Japan. Japanese Journal of Environmental Education 19(1), 68-75.

Ohori, S. and Mizushima, E. (2012) Museology, Japan: Gakubunsya press.

Okazaki, A. (2017) A Novel Approach for Environmental Workshops for People Including Both Adults and Children: Bingo Games Combined with Environmental Keywords and Quiz. Japanese Journal of Science Communication 2, 8-108.

Omura, A. (2016) Dissection and Observation of Penaeus monodon: Approaches for the improvement of observation skills through sketching. Bulletin of Teikyo University of Science, 12, 155-160.

Omura, A. and Endo, H. (2016). The functional-morphological adaptive strategy of digestive organs of decapodiform cephalopods. Journal of Veterinary Medical Science, 78(1), 43-47. https://doi.org/10.1292/jvms.150185

Omura, A., Anzai, W. and Endo, H. (2014) Functional and Morphological Variety in Trunk Muscles of Urodela. Journal of Veterinary Medical Science, 76(2), 159-167. https://doi.org/10.1292/jvms.13-0211

Omura, A., Anzai, W., Koyabu, D. and Endo, H. (2015) Ontogenetic changes of trunk muscle structure in the Japanese black salamander (Hynobius nigrescens). Journal of Veterinary Medical Science, 77(8), 931-936. https://doi.org/10.1292/jvms.15-0011

Omura, A., Anzai, W., Koyabu, D. and Endo, H. (2015). Positional strategy of trunk muscles among aquatic, semiaquatic and terrestrial species in Urodela. Journal of Veterinary Medical Science, 77(9), 1043-1048. https://doi.org/10.1292/jvms.14-0320

Omura, A., Ejima, K., Honda, K., Anzai, W., Taguchi, Y., Koyabu, D. and Endo, H. (2015). Locomotion pattern and trunk musculoskeletal architecture among Urodela. Acta Zoologica, 96(2), 225-235. https://doi.org/10.1111/azo.12070

Papastergiou, M. (2009). Digital Game-Based Learning in high school Computer Science education: Impact on educational effectiveness and student motivation. Computers and Educatoin, 52, 1-12. https://doi.org/10.1016/j.compedu.2008.06.004

Rahm, J. and Ash, D. (2008). Learning environments at the margin : Case studies of disenfranchised youth doing science in an aquarium and an after-school program. Learning Environmental Research, 11, 49-62. https://doi.org/10.1007/s10984-007-9037-9

Saeki, H. (2016). Dissection Practice of small dried sardines. Japanese Journal of Science Educational Research, 57(3), 273280. https:// doi.org/10.11639/sjst.16052

Saeki, H., Imamura, T., Matsunaga, T. and Mizuno, S. (2013). The educational effect and usage of teaching materials of Chirimen Monster. Science Teaching Research, 54(1), 27-36. https://doi.org/10.11639JRSE12024

Seonah, O. and Muto, T. (1998). The Effects of Views of Nature and Experience of Nature on One's Environmental Values. Environmental Education, 7(2), 2-13.

Sfakiotakis, M., Lane, D. M. and Davies, J. B. C. (1999). Fish Swimming Techniques. Journal of Oceanic Engineering, 24(2), 237-252. https://doi.org/10.1109/48.757275

Shimada, H. (2009). Environmental Education Using Rock Shells in Lower Secondary Scool Science. Kumamoto University Repository System, 58, 1-6.

Suarez, A. V., and Tsutsui, N. D. (2004). The Value of Museum Collections for Research and Society. Bioscience, 54(1), 66-74. https://doi.org/10.1641/0006-3568(2004)054[0066:TVOMCF]2.0.CO;2

Sunaga, K. (2010) Several understandings and practical tasks of active learning: focusing on the concept “activeness". Kansai University Institution Repository, 1, 1-11. http://hdl.handle.net/10112/2939

Susono, H., Simoura, T., Oda, K. and Ono, E. (2006). How to create Digital Storytelling by using still pictures. Research report of JET Conferences, 5, 51-56.

Suzuki, K. and Nishi, K. (2010). Aquariology. Japan: Tokai University Press.

Uchida, S., Arai, K. and Nishida, K. (2014). Aquariums in Japan. Japan: Tokyo University Press. 